\title{
Modelling of matrix diffusion in a tracer test in concrete
}

\author{
M. Carme Chaparro - Maarten W. \\ Saaltink • Josep M. Soler • Luit Jan \\ Slooten · Urs K. Mäder
}

the date of receipt and acceptance should be inserted later

\begin{abstract}
A laboratory-scale tracer test has been carried out to improve the characterization of the transport properties of the concrete from the Radioactive Waste Disposal Facility at El Cabril (Spain). High entry pressure was employed in order to perform the experiment in a reasonable time span. Lithium, bromide and deuterium were used as tracers. The conceptual model considered matrix diffusion between a mobile pore domain, where water can flow, and an immobile zone without any advective transport. Three geometries have been compared, considering the immobile zone as slabs, spheres or tubes. Porosity of the mobile zone and characteristic time were estimated by calibrating the model results to the measured breakthrough curves of deuterium and bromide. The calculated values showed that the characteristic time depends on the geometry and similar porosity of the mobile zone was estimated for all geometries. The double-porosity conservative transport model could reproduce the deuterium breakthrough curve. However, the bromide behaviour could not be reproduced even when linear retardation was applied.
\end{abstract}

Keywords double porosity $\cdot$ tracer test $\cdot$ concrete $\cdot$ conservative transport . numerical model

\section{List of symbols}

$$
A_{\text {matrix }} \text { matrix area }\left(\mathrm{m}^{2}\right)
$$

M. Carme Chaparro $\varangle$. Maarten W. Saaltink

GHS, Dept Geotechnical Engineering and Geosciences, UPC. Universitat Politècnica de Catalunya. BarcelonaTech, Jordi Girona 1-3 Building D2 08034 Barcelona Spain.

Tel.: +34 934011858

E-mail: m.carme.chaparro@upc.edu

Josep M. Soler · Luit Jan Slooten

GHS (UPC-CSIC), Institute of Environmental Assessment and Water Research (IDAEACSIC), Jordi Girona 18, 08034 Barcelona Spain.

Urs K. Mäder

Rock-Water Interaction, Institute of Geological Sciences, University of Bern, Baltzerstrasse 1-3, CH-3012 Bern Switzerland. 


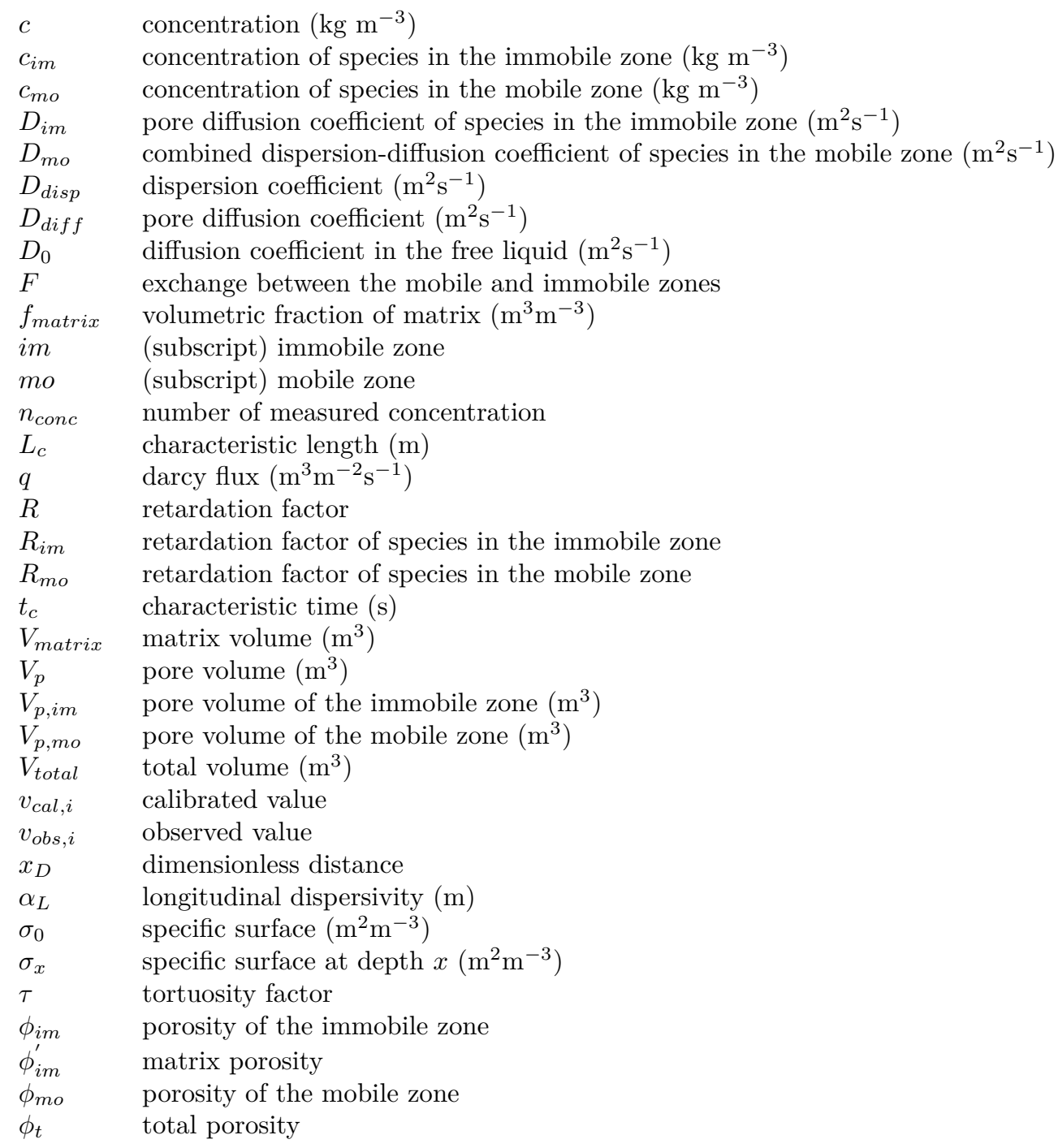

21 Introduction

3 Cementitious materials are used as barriers in radioactive waste storage. An example 4 is the low and intermediate level radioactive waste facility at "El Cabril", Southern 5 Spain (Zuloaga et al 2006), which also motivates this work. It is important to understand the processes and parameters for solute transport in concrete. Concrete is a porous material that consists of cement paste and coarse and fine aggregates. The cement paste is composed of the hydration products of the cement, mainly CSH (calcium silicate hydrate), portlandite, ettringite and/or monosulfate together with smaller amounts of other hydration products. The way these phases are arranged geometrically can be quite complex. The microstructure of concrete around the aggregates is different from that of the bulk cement. In this so called interfacial transition zone the porosity can be higher (Taylor 1997; Scrivener et al 2004). 


\section{$44 \quad 2$ Experimental set up}

45 511 .

\subsection{Material}

\subsection{Sample preparation}

Most studies consider diffusion as the main transport mechanism in cement based materials and use tracer tests to study it. Traditionally, diffusion coefficients of different solutes are determined by means of diffusion cells, where the samples can only be a few $\mathrm{mm}$ thick because of the slow diffusion in this kind of material. For instance, Goto and Roy (1981) and Atkinson and Nickerson (1984) studied the effect of water/cement ratio, temperature, electric potential and/or curing time on the diffusion coefficient of $\mathrm{Na}^{+}, \mathrm{Cl}^{-}, \mathrm{I}^{-}$and $\mathrm{Cs}^{+}$in cement pastes. The diffusion coefficients were obtained analytically. Tits et al (2003) used numerical models to analyze their diffusion experiments with tritium and $\mathrm{Na}^{+}$and obtained the effective diffusion coefficient and the capacity factor of a high permeability cement. Although they used a single porosity model, they suggested the existence of a second type of porosity. Also, Kamali-Bernard et al (2009) used numerical models for tritiated water diffusion tests in cementitious materials to investigate the changes in their microstructure due to mineral leaching. In recent years models have been proposed that take into account the heterogeneity caused by the complex structure of concrete. An example is the work of Dridi (2013), who made numerical models of tritium transport in cement pastes and concrete, explicitly simulating the geometry of the aggregates, interfacial transition zone and cement paste.

All these studies focused on diffusion, which makes sense in most cases, because concrete has a low permeability and water flow is often negligible. However, when concrete is exposed to evaporation, pressure gradient may become high and flow of water and, hence, advection and dispersion play a more important role. This is the case of the facility at "El Cabril" (Zuloaga et al 2006; Chaparro and Saaltink 2014; Chaparro et al 2015). In this work we study solute transport in concrete taking into account diffusion, dispersion and advection. We treat the heterogeneity of concrete by means of matrix diffusion. Matrix diffusion has been applied to hydrogeological studies, particularly fractured aquifers (Carrera et al 1998; Jakob et al 2003; Heer 2004). The goal of this work is to improve the understanding of processes and transport properties in concrete where advection is important. In particular, we studied the concrete from the radioactive waste disposal facility at "El Cabril".

The concrete was manufactured by ENRESA (Spanish Nuclear Waste Management Company) following the same procedure as in the Radioactive Waste Disposal Facility at "El Cabril" (Spain). It has a low intrinsic permeability, which is between $4.5 \times 10^{-18}$ and $8 \times 10^{-19} \mathrm{~m}^{2}$, measured using a constant-head permeameter with water, and its $\mathrm{w} / \mathrm{c}$ ratio was 0.44 . The composition of the concrete is shown in table

A cylindrical sample with a diameter of $5.5 \mathrm{~cm}$ and $10 \mathrm{~cm}$ in length was drilled from a cylindrical concrete block cured during approximately 6 months at room conditions. The sample was cut in three parts. The first one had a length of $5.5 \mathrm{~cm}$ and was 
Table 1 Concrete composition. Values within parenthesis refer to minimum and maximum size $(\mathrm{mm})$ of the aggregate or sand.

\begin{tabular}{ll}
\hline Component & Quantity \\
\hline Aggregates (4/16) & $1023 \mathrm{~kg} / \mathrm{m}^{3}$ \\
Sand $(0 / 4)$ & $434 \mathrm{~kg} / \mathrm{m}^{3}$ \\
Sand $(0 / 2)$ & $403 \mathrm{~kg} / \mathrm{m}^{3}$ \\
Ordinary Portland Cement I-42.5 R/SR & $400 \mathrm{~kg} / \mathrm{m}^{3}$ \\
Rheobuild 1222 additive (superplasticizer) & $6.5 \mathrm{~kg} / \mathrm{m}^{3}$ \\
Water & $175 \mathrm{~L} / \mathrm{m}^{3}$ \\
\hline
\end{tabular}

used to perform the infiltration test. The second one was used to measure the water content using an oven at $105^{\circ} \mathrm{C}$ and had a length of approximately $2.5 \mathrm{~cm}$. The last one was not used.

The specimen used to perform the infiltration test was waterproofed in order to avoid infiltration of water through its lateral sides. Firstly, the lateral sides of the sample was covered with a layer of mortar to fill large pores. Then, a titanium filter, with a porosity of 0.28 , and a titanium cylindrical piece were placed at both the bottom and the top of the sample. Finally, the setup was wrapped with several layers of Teflon, two layers of latex and several layers of insulating tape. Following this procedure, the core was ready to be introduced into the infiltration apparatus.

\subsection{The infiltration test}

We used a high-pressure core infiltration apparatus in order to perform the tracer tests in a reasonable time span. This device not only has been used to study tracer transport but also to investigate chemical rock-water interaction (Adler et al 2001; Mäder et al 2004, 2006; Soler and Mäder 2007, 2010; Dolder et al 2013; Jenni et al 2013). It was composed of three parts: the pressure vessel, the confining system and the infiltration system (Figure 1). The pressure vessel surrounds the core, containing the sample, confined with water of a pressure of 50 bars. This pressure was applied by connecting the pressure vessel to the confining system containing highly pressurized argon. The infiltration system consisted of pressurized helium (20 bars) connected to two tanks containing infiltration solutions, one with and one without tracers. Through a valve either one or the other solution could be injected into the sample. Both solutions consisted of distilled water with $10.6 \mathrm{~g} / \mathrm{l}$ of $\mathrm{KOH}$ and 0.1 $\mathrm{g} / \mathrm{l}$ of $\mathrm{Ca}(\mathrm{OH})_{2}$, which gave a $\mathrm{pH}$ of 13.4 . The tracer solution also had $155 \mathrm{mg} / \mathrm{l}$ of bromide and $576 \mathrm{mg} / \mathrm{l}$ of deuterium together in the same solution. We performed the tracer test using a pulse injection. To do so, the solution without tracers was injected into the core during 4 days. Then, we switched to the tracer solution during 2 days. Finally, we injected again the solution without tracers during several weeks. The water leaving the outlet was collected by syringes. Afterwards, the solutions were analysed. Deuterium was analysed using Picarro L2130-i which is an isotopic water analyser for $\delta \mathrm{D}$ and $\delta^{18} \mathrm{O}$. Bromide and lithium were analysed using Ion Chromatog- 
raphy analysis with an 850 ProfIC An/Cat apparatus with $\mathrm{MCS} \mathrm{CO}_{2}$ Suppression from Metrohm.

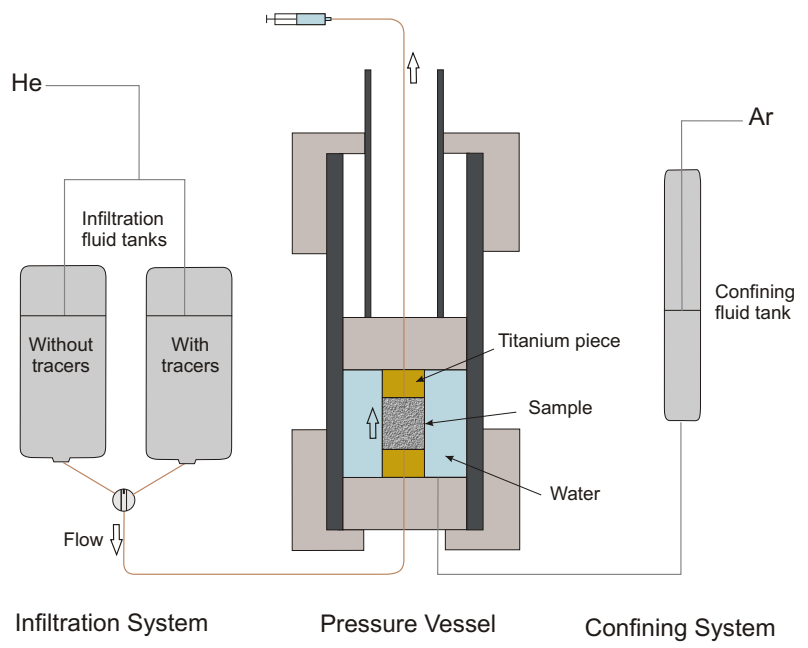

Fig. 1 Scheme of the infiltration apparatus.

\section{Conceptual model}

Following Carrera et al (1998) our conceptual model is based on matrix diffusion, which is a transport mechanism that allows solute transfer between a mobile zone and an immobile zone. The mobile zone represents the well connected pores with solute transport by advection, dispersion and diffusion. The immobile zone represents the matrix, where solutes are transported only by diffusion. We compared three geometries of the porous medium so as to represent the immobile zone: slabs, spheres and tubes (Figure 2; Carrera et al (1998)). A characteristic length, $L_{c}$, defines the size of the immobile zone for all geometries.

\subsection{Parameters definitions}

The conceptual model considers double porosity, which means that there is a porosity for the mobile zone, and another one for the immobile zone. The sum of the mobile and immobile porosities is the total porosity (Eq. 1, Eq. 2 and Eq. 3).

$$
\begin{gathered}
\phi_{t}=\frac{V_{p}}{V_{\text {total }}}=\phi_{m o}+\phi_{i m} \\
\phi_{m o}=\frac{V_{p, \text { mo }}}{V_{\text {total }}}
\end{gathered}
$$


a) Slabs

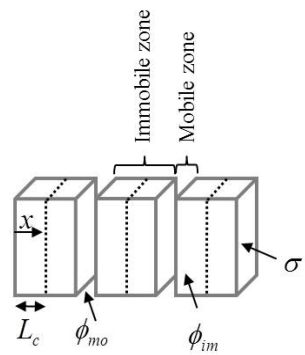

b) Spheres

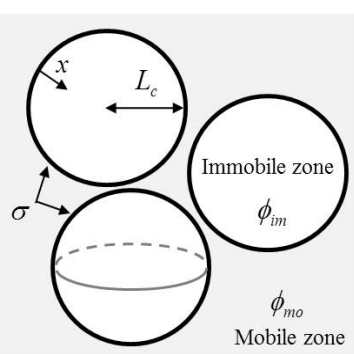

c) Tubes
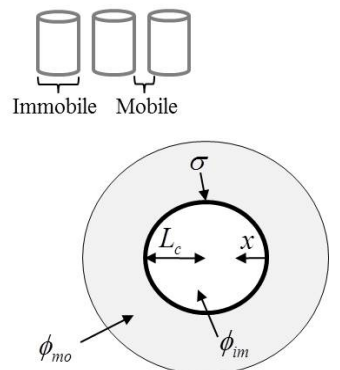

Fig. 2 Geometries (immobile and mobile zones) for each conceptual model.

$$
\phi_{i m}=\frac{V_{p, i m}}{V_{\text {total }}}=\frac{V_{p, i m}}{V_{\text {matrix }}} \frac{V_{\text {matrix }}}{V_{\text {total }}}=\phi_{\text {im }}^{\prime} f_{\text {matrix }}
$$

Subscripts mo and $i m$ refer to mobile and immobile respectively. $\phi_{t}$ is the total porosity, $\phi_{m o}$ is the porosity of the mobile zone, $\phi_{i m}$ is the porosity of the immobile zone, $\phi_{i m}^{\prime}$ is the porosity of the matrix. $V_{\text {total }}$ is the total volume $\left(\mathrm{m}^{3}\right), V_{p}$ is the pore volume $\left(\mathrm{m}^{3}\right), V_{p, m o}$ and $V_{p, i m}$ are the pore volume of the mobile and immobile zone respectively $\left(\mathrm{m}^{3}\right), V_{\text {matrix }}$ is the volume of the matrix (e.g. $A_{\text {matrix }} L_{c}$ for slabs, in $\left.\mathrm{m}^{3}\right)$ and $f_{\text {matrix }}$ is the volumetric fraction of the matrix $\left(\mathrm{m}^{3} \mathrm{~m}^{-3}\right)$.

A useful transport parameter is the characteristic time for diffusion in the immobile zone over a characteristic length. It can be formulated as:

$$
t_{c}=\frac{L_{c}^{2}}{D_{i m}}
$$

$t_{c}$ is the characteristic time (s), $L_{c}$ is the characteristic length $(\mathrm{m})$ and $D_{i m}$ is the diffusion coefficient of a species in the mobile zone $\left(\mathrm{m}^{2} \mathrm{~s}^{-1}\right)$.

Another parameter is the specific surface, which is the interface area between the mobile and immobile zone divided by the total volume of the concrete sample. It depends on the geometry (Figure 2, Eq. 5, Eq. 6, Eq. 7 and Eq. 8).

$$
\begin{gathered}
\sigma_{0}=\frac{A_{\text {matrix }}}{V_{\text {matrix }}} \frac{V_{\text {matrix }}}{V_{\text {total }}} \\
\text { Slabs: } \sigma_{0}=\frac{1}{L_{c}} f_{\text {matrix }} \\
\text { Spheres: } \sigma_{0}=\frac{3}{L_{c}} f_{\text {matrix }} \\
\text { Tubes: } \sigma_{0}=\frac{2}{L_{c}} f_{\text {matrix }}
\end{gathered}
$$


3.2 Mass balance equations

The numerical model solves the balance equations for the mobile and immobile zones (Eq. 9 and Eq. 10).

$$
\begin{gathered}
R_{m o} \phi_{m o} \frac{\partial c_{m o}}{\partial t}=\phi_{m o} D_{m o} \frac{\partial^{2} c_{m o}}{\partial y^{2}}-q \frac{\partial c_{m o}}{\partial y}+F \\
\text { with } \quad R=1 \quad \text { (no retardation) } \\
R_{i m} \phi_{i m} \sigma_{x} \frac{\partial c_{i m}}{\partial t}=\phi_{i m} \frac{\partial}{\partial x}\left(D_{i m} \sigma_{x} \frac{\partial c_{i m}}{\partial x}\right) \\
\text { with }\left.\quad c_{i m}\right|_{x=0}=c_{m o}
\end{gathered}
$$

$x$ refers to the direction in which matrix diffusion takes place (from mobile to immobile zones) and $y$ refers to the direction where advection takes place in the mobile zone. The left hand term for both equations corresponds to storage. $R$ is the retardation factor and it is defined as:

$$
R=1+\frac{\left(1-\phi_{i m}\right)}{\phi_{i m}} \rho_{\text {solid }} k_{d}
$$

$\rho_{\text {solid }}$ is the solid density and $k_{d}$ is the distribution coefficient.

$\sigma_{x}$ is the specific surface at distance $x$, defined as:

$$
\text { Slabs: } \sigma_{x}=\sigma_{0}
$$

$$
\begin{aligned}
\text { Spheres: } & \sigma_{x}=\sigma_{0} \frac{\left(L_{c}-x\right)^{2}}{L_{c}^{2}} \\
\text { Tubes: } \quad \sigma_{x} & =\sigma_{0} \frac{L_{c}-x}{L_{c}}
\end{aligned}
$$

The first term of the right hand side of Eq. 9 corresponds to the sum of diffusion and dispersion, where $c_{m o}$ is the concentration of spices in the mobile zone $\left(\mathrm{kg} \mathrm{m}^{-3}\right)$ and $D_{m o}$ is the combined dispersion-diffusion coefficient of species in the immobile zone $\left(\mathrm{m}^{2} \mathrm{~s}^{-1}\right)$. This is defined as:

$$
\begin{gathered}
D_{m o}=D_{\text {disp }}+D_{\text {diff }} \\
D_{\text {disp }}=\alpha_{L} q \\
D_{\text {diff }}=\tau D_{0}
\end{gathered}
$$

$D_{\text {disp }}$ and $D_{\text {diff }}$ are the dispersion coefficient and pore diffusion coefficient respectively $\left(\mathrm{m}^{2} \mathrm{~s}^{-1}\right), \alpha_{L}$ is the longitudinal dispersivity $(\mathrm{m}), q$ is the darcy flux $\left(\mathrm{m}^{3} \mathrm{~m}^{-2} \mathrm{~s}^{-1}\right), \tau$ is the tortuosity factor and $D_{0}$ is the diffusion coefficient in the free liquid $\left(\mathrm{m}^{2} \mathrm{~s}^{-1}\right)$.

The right hand side of Eq. 10 refers to matrix diffusion, where $c_{i m}$ is the concentration of species in the immobile zone $\left(\mathrm{kg} \mathrm{m}^{-3}\right), D_{i m}$ is defined like in Eq. 17. 
The third term of Eq. 9 corresponds to advection and the last one, $F$, is the exchange between the mobile and immobile zones which is defined as:

$$
F=\sigma_{0} \phi_{i m}^{\prime} D_{i m} \frac{\partial c_{i m}}{\partial x}
$$

We can define a dimensionless distance, $x_{D}$, as:

$$
x_{D}=\frac{x}{L_{c}}
$$

and taking into account the definitions of specific surface (Eq. 6, Eq. 7 or Eq 8) and the characteristic time (Eq. 4), we can rewrite the balance equation for the immobile zone (Eq. 10) as:

$$
\begin{gathered}
\text { Slabs: } R_{i m} \phi_{i m} \frac{\partial c_{i m}}{\partial t}=\phi_{i m} \frac{1}{t_{c}} \frac{\partial^{2} c_{i m}}{\partial x_{D}^{2}} \\
\text { Spheres: } \quad R_{i m} \phi_{i m}\left(1-x_{D}\right)^{2} \frac{\partial c_{i m}}{\partial t}=\phi_{i m} \frac{1}{t_{c}} \frac{\partial}{\partial x_{D}}\left(1-x_{D}\right)^{2} \frac{\partial c_{i m}}{\partial x_{D}} \\
\text { Tubes: } \quad R_{i m} \phi_{i m}\left(1-x_{D}\right) \frac{\partial c_{i m}}{\partial t}=\phi_{i m} \frac{1}{t_{c}} \frac{\partial}{\partial x_{D}}\left(1-x_{D}\right) \frac{\partial c_{i m}}{\partial x_{D}}
\end{gathered}
$$

By substituting the definitions of the specific surface (Eq. 6, Eq. 7 or Eq. 8), the immobile porosity (Eq. 3) and the characteristic time (Eq. 4) into Eq. 18, we obtain the following exchange term for each geometry:

$$
\begin{gathered}
\text { Slabs: } \quad F=\phi_{i m} \frac{1}{t_{c}} \frac{\partial c_{i m}}{\partial x_{D}} \\
\text { Spheres: } \quad F=3 \phi_{i m} \frac{1}{t_{c}} \frac{\partial c_{i m}}{\partial x_{D}} \\
\text { Tubes: } \quad F=2 \phi_{i m} \frac{1}{t_{c}} \frac{\partial c_{i m}}{\partial x_{D}}
\end{gathered}
$$

Using a dimensionless distance our model can be described by means of 4 parameters: the immobile and mobile porosities, the characteristic time and the retardation factor.

\section{Numerical model}

The simulations were carried out with PROOST (Process Oriented Optimization and Simulation Tool; Slooten et al 2010), which is a general purpose hydrological modelling tool. 


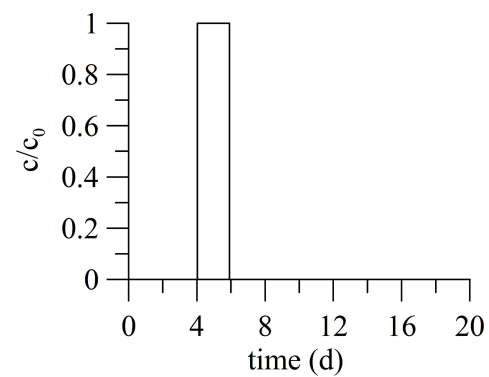

4.1 Geometry and mesh

A two-dimensional domain represented by a finite element mesh was used. We distinguished a mobile zone and an immobile zone. The mobile zone was represented by the $y$ axis with 51 nodes and 50 one-dimensional elements. From each of these nodes there is a series of one-dimensional elements in the $x$ axis representing the immobile zone. Each immobile zone was composed of 10 nodes and 10 one-dimensional elements with dimensionless lengths varying from 0.0025 to 0.3 . Therefore, the whole mesh had 561 nodes and 560 elements.

\subsection{Boundary conditions and initial conditions}

A prescribed time-dependent mass flux boundary condition $(q c)$ was applied at the inlet. Both flux $(q)$ and concentration $(c)$ vary in time (Figure 3). Initial concentration in the domain were zero for bromide and $4.346 \mathrm{mg} / \mathrm{l}$ for deuterium.

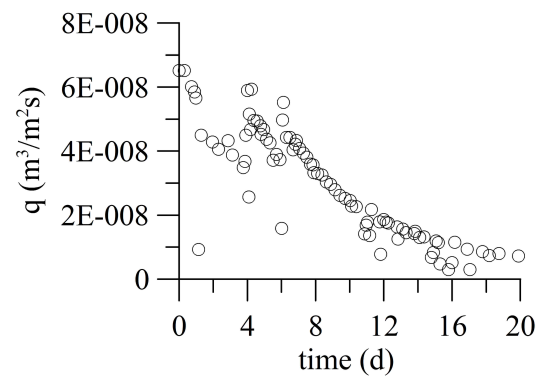

Fig. 3 Boundary conditions. Evolution of flux and concentration.

a) Flux

\subsection{Data and calibration}

Prior to a calibration of the matrix diffusion model of section 3 , we calibrated a single porosity model without matrix diffusion to see whether this simpler model was capable of reproducing the experimental data (Figure 4).

Calibration of the matrix diffusion models were performed by fitting the model to the measured breakthrough curves of bromide and deuterium. Some parameters were fixed in the model and some of them were calibrated. We used a porosity of 0.17 (Eq. 1), obtained from experimental data and numerical models ((Villar et al 2009; Chaparro et al 2015)) and calibrated a dispersivity of $0.001 \mathrm{~m}$ (Eq. 16) and pore diffusion coefficient of $5 \times 10^{-10} \mathrm{~m}^{2} \mathrm{~s}^{-1}\left(D_{\text {diff }}\right.$, Eq. 17). These values gave good fits for the double porosity model. For deuterium we calibrated the porosity of the mobile zone $\left(\phi_{m o}\right.$; Eq. 2$)$ and the characteristic time $\left(t_{c}\right.$; Eq. 4$)$. For bromide we first tried to calibrate the characteristic time, porosity of the mobile zone and the retardation 
coefficient of the immobile zone $\left(R_{i m}\right.$; Eq. 20, Eq. 21 or Eq. 22). The retardation coefficient of the mobile zone, $\left(R_{m o}\right)$, was set to 1 , because data show the same early arrival time for both tracers (Figure 4). However, the results showed that the porosity of the mobile zone and retardation coefficient were correlated, which means that only one of them can be estimated. Therefore, we fixed the porosity of the mobile zone at a value equal to that obtained from the deuterium breakthrough curve. So, we calibrated the retardation coefficient for the immobile zone and the characteristic time. We use an automated calibration based on the minimization of the following objective function:

$$
O F=\sum_{i=1}^{n_{\text {conc }}}\left(v_{o b s, i}-v_{c a l, i}\right)^{2}
$$

$v_{\text {obs }}$ and $v_{\text {calc }}$ are the observed and calculated values respectively and $n_{\text {conc }}$ is the number of measured concentrations.

The numerical method for this optimization was Marquardt's method (Marquardt 1963).

\section{Results and discussion}

\subsection{Experimental data}

Lithium, bromide and deuterium were used as tracers. The breakthrough curves obtained for deuterium and bromide and the evolution of the cumulative mass (recovery) are displayed in Figure 4. Few data were obtained for lithium because the concentrations of the majority of the samples were under the detection limit of the Ion Chromatography analysis. Hence, the lithium concentrations were not used in the numerical models due to the lack of data. Note that the peak for bromide is lower than the one for deuterium. While the recovery for deuterium is $94 \%$, the one for bromide is $67 \%$. It seems that bromide suffers some form of retention which reduces its mobility.

\subsection{Numerical model results}

Figure 4 compares experimental data with the single porosity model. The breakthrough curves of bromide and deuterium and the cumulative mass are showed. The single porosity model cannot reproduce the measured data. It overestimates concentration at early time arrival and cannot reproduce the tailing at later times. Therefore, a double porosity model is necessary.

Figure 5 compares best fits of the model taking into account matrix diffusion with the experimental data. The relative concentration, the log-log plot of the breakthrough curves and the cumulative mass with respect to time are displayed for each tracer (deuterium and bromide), and also for each geometry (slabs, spheres and tubes). Model results for deuterium fitted perfectly well the experimental data. Hence, the deuterium results show that the double porosity conceptual model can be applied in order to model conservative transport in concrete. Theoretically a $t^{-3 / 2}$ dependency on a log-log plot is an indication of matrix diffusion (Hadermann and 
a) Breakthrough curves

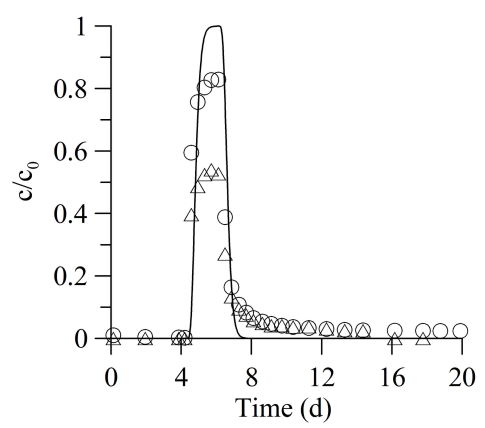

b) Recoveries

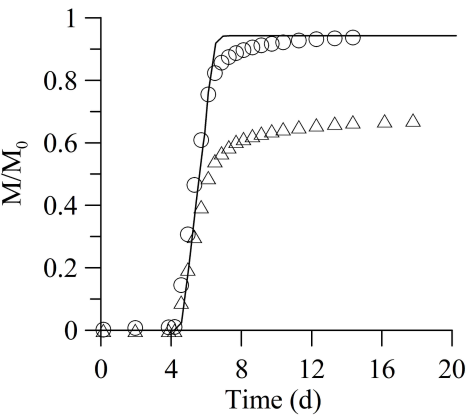

$\triangle$ Bromide

○ Deuterium

- Model

Fig. 4 Evolution of relative concentration and cumulative mass for deuterium and bromide. Single porosity model results (lines) are compared with the experimental data (points).

Heer 1996; Haggerty et al 2000). Figure 5 do not clearly show such dependency. It would require longer time periods with a tailing covering several orders of magnitude. In our experiments, this would cause problems with respect to precision and detection limits of concentration measurements. To avoid this, larger concentration of tracers should have been added. Moreover, the flux of water in our test is not constant which also could have an effect on the shape of the breakthrough curve. Contrary to deuterium, the bromide data cannot be reproduced. Even when linear sorption is applied (Eq. 20, Eq. 21 or Eq. 22), the numerical model overestimates the recovered mass. Furthermore, slightly different results are obtained for each geometry. This suggests that some other processes or reactions are at work. It is difficult to determinate these processes from our results. However, some research has been published on anionic uptake in cementitious materials. Baur and Johnson (2003) found a strong sorption of selenate to monosulfate (AFm); they suggest a substitution of sulfate by selenate in monosulfate. Results obtained by Bonhoure et al (2006), who also investigated the uptake of selenate, agreed with the previous finding. The iodide uptake by monosulfate was investigated by Aimoz et al (2012); they found that the formation of $\mathrm{AFm}-\mathrm{I}_{2}$ could retard the mobility of ${ }^{129} \mathrm{I}$. Hence, we suggest that similarly to selenate and iodide, the retardation of bromide could be due to uptake by monosulfate. Probably this cannot be described well enough by the linear retardation of our model. More research is needed in order to understand the retention of bromide.

For both tracers the breakthrough curves are similar for each geometry of the immobile zone (slabs, spheres and tubes). This means that we cannot deduce the geometry from concentration measurements at the outlet. However, the models reveal that concentrations in the immobile zone do depend on the type of geometry. This is illustrated in figure 6. It shows the relative concentrations of deuterium versus dimensionless distance (Eq. 19) at the inlet of the sample $(\mathrm{y}=0 \mathrm{~cm})$ for three different 
times (fourth, sixth and eighth day). For all geometries, just after the injection of the tracer ( $\mathrm{t}=4$ days) the relative concentration at the inlet is 1 . Thereafter, the concentration of deuterium is moving towards the outlet of the sample and to the immobile zone ( $x$ axis), obtaining the maximum concentration in the breakthrough curve after 6 days. From then on, the concentration of deuterium in the immobile zone is higher than that in the mobile zone and deuterium diffuses back into the mobile zone, causing the tail in the breakthrough curve (Figure 5). Although the concentrations in the mobile zones are very similar in the three geometries, the slab geometry shows the deepest penetration of deuterium into the immobile zone. Spheres gives the shortest penetration.

The parameters obtained from the calibration of both tracers are shown in table 2. For deuterium the calibrated parameters were the mobile porosity $\left(\phi_{m o}\right.$; Eq. 2$)$ and the characteristic time $\left(t_{c}\right.$; Eq. 4). The immobile porosity was calculated from the total porosity and the mobile porosity (Eq. 1). The calibrated porosity of the mobile phase is similar for all the geometries. It is much smaller than the porosity of the immobile phase. There is less pore volume in the mobile zone, but the connection between pores is probably better than in the immobile zone. Values obtained for the characteristic time are different for each geometry due to the specific surface, which depends on the geometry (Figure Eq. 6, Eq. 7 or Eq. 8). Note that the spheres give a characteristic time about 8 times larger than that of slabs, while characteristic time for tubes is intermediate between spheres and slabs. This partly reflects the factors 1, 3 and 2 in Eq. 23, 24 and 25 respectively. Partly it reflects the deeper penetration into the immobile zone, hence lower concentration gradient $\left(\partial c_{i m} / \partial x_{D}\right)$ in the slabs (Figure 6). Large characteristic times were obtained for bromide because of retention. Similar values of retardation factor are calculated by the model. We cannot estimate a characteristic length independently of the diffusion coefficient of the immobile zone. However, considering a characteristic length of $100 \mu m$ (based on electron microscopy observations) we would obtain a pore diffusion coefficient between $2.8 \times 10^{-15}$ and $3.6 \times 10^{-16} \mathrm{~m}^{2} \mathrm{~s}^{-1}$, depending on the geometry. These values are low compared to other diffusion coefficient measured in cementitious materials (Goto and Roy (1981); Dridi (2013); Du et al (2014)). One explanation could be a higher characteristic length. An increase of the characteristic length by a factor of 10 would increase the diffusion coefficient with a factor of 100. Another explanation is that our pore diffusion coefficient only represents small and poorly connected pore in the C-S-H gel that we assume constitutes the immobile zone, whereas the diffusion coefficients of Goto and Roy (1981); Dridi (2013); Du et al (2014) represent the whole domain.

\section{Conclusions}

With the aim of improving the characterization of the transport properties of the concrete from the Radioactive Waste Disposal Facility at El Cabril (Spain), we performed a tracer test in a high-pressure core infiltration device using lithium, bromide and deuterium as tracers. We modelled the breakthrough curves of deuterium and bromide obtained from the experimental data. The conceptual model takes into account matrix diffusion, considering a mobile zone where advection, dispersion and diffusion are the transport mechanisms and an immobile zone where there is only diffusion. We assumed the immobile zone to consist of slabs, spheres or tubes. The 
Table 2 Calibrated parameters by the numerical models.

\begin{tabular}{cccccc}
\hline Tracer & Geometry & $\phi_{m o}$ & $\phi_{i m}$ & $t_{c}(\mathrm{~d})$ & $\mathrm{R}$ \\
\hline Deuterium & Slabs & $0.029 \pm 0.002$ & 0.141 & $40.7 \pm 6.0$ & \\
& Spheres & $0.027 \pm 0.002$ & 0.143 & $316.0 \pm 58.6$ & \\
& Tubes & $0.027 \pm 0.002$ & 0.143 & $140.9 \pm 23.3$ & \\
Bromide & Slabs & & & & \\
& Spheres & & & $2232.9 \pm 477.2$ & $73.4 \pm 28.9$ \\
& Tubes & & & $1398.4 \pm 308.6$ & $91.2 \pm 32.6$ \\
& & & & & \\
\hline
\end{tabular}

models have been calibrated acquiring the mobile porosity and characteristic time. Analysing the results, we obtain the following conclusions:

- A single porosity model without matrix diffusion cannot reproduce the experimental data.

- Excellent agreement between numerical model and experimental data for deuterium has been obtained. The double porosity conceptual model can be applied to model conservative transport in concrete.

- Bromide behaviour cannot be reproduced using a conservative transport model. Even when a retardation coefficient is applied the results are not satisfactory. Similarly to Baur and Johnson (2003), Bonhoure et al (2006) or Aimoz et al (2012), this could be caused by an uptake of bromide by the monosulfate phase.

- From the calibration of deuterium, similar porosities are obtained for all geometries. We found porosities of the immobile zone much higher than that of the mobile zone (about 0.14 and 0.028 . respectively). However, the characteristic time depends on the geometry considered; the values obtained are between 40.7 and 316 days.

- For conservative tracers, such as deuterium, the fits for the three geometries were practically identical. This means that this type of tracer test cannot be used to determine the geometry of the immobile zone. To do so, a detailed structural characterization of the concrete should be performed. Theoretically, the geometry could also be deduced if tracer concentration distributions inside the immobile zone of the concrete could be measured. However, to our knowledge there is no experimental method for obtaining these types of measurements.

- Our findings suggest that double porosity models should be taken into account in models of transport in concrete, such as transport of radioactive contaminants in the concrete of the facility at "El Cabril".

Acknowledgements The authors would like to thank Florian Dolder and Andreas Jenni for their help in the laboratory. We acknowledge financial support of the Spanish Ministry of Economy and Competitivity through the project HEART (CGL2010-18450), also ENRESA (Spanish Nuclear Waste Management Company) and a Research Grant from the Technical University of Catalonia (FPU-UPC). 


\section{References}

Adler M, Mäder U, Waber H (2001) Core infiltration experiment investigating high-pH alteration of low-permeability argillaceous rock at $30^{\circ} \mathrm{C}$. In: Cidu, R (Ed), Proceedings WRI-10 (10th International Symposium on Water-Rock Interaction) Balkema, Villasimius, Italy pp 1299-1302

Aimoz L, Wieland E, Taviot-Guého C, Dähn R, Vespa M, Churakov SV (2012) Structural insight into iodide uptake by AFm phases. Environmental Science \& Technology 46(7):38743881, DOI 10.1021/es204470e, http://dx.doi.org/10.1021/es204470e

Atkinson A, Nickerson AK (1984) The diffusion of ions through water-saturated cement. Journal of Materials Science 19(9):3068-3078

Baur I, Johnson CA (2003) Sorption of selenite and selenate to cement minerals. Environmental Science \& Technology 37(15):3442-3447, DOI 10.1021/es020148d, http://dx.doi.org/10.1021/es020148d

Bonhoure I, Baur I, Wieland E, Johnson CA, Scheidegger AM (2006) Uptake of $\mathrm{Se}(\mathrm{IV} / \mathrm{VI})$ oxyanions by hardened cement paste and cement minerals: An X-ray absorption spectroscopy study. Cement and Concrete Research 36(1):91-98, DOI http://dx.doi.org/10.1016/j.cemconres.2005.05.003

Carrera J, Sánchez-Vila X, Benet I, Medina A, Galarza G, Guinerà J (1998) On matrix diffusion: Formulations, solution methods and qualitative effects. Hydrogeology Journal 6(1):178-190

Chaparro MC, Saaltink MW (2014) Modelling of multiphase flow in concrete cells of the radioactive waste storage facility at El Cabril (Spain). 2nd International symposium on cement-based materials for nuclear waste (Nuwcem), Avignon, France pp 1-8

Chaparro MC, Saaltink MW, Villar MV (2015) Characterization of concrete by calibrating thermo-hydraulic multiphase flow models. Transport in Porous Media 109:147-167, DOI $10.1007 / \mathrm{s} 11242-015-0506-9$

Dolder F, Mäder U, Jenni A, Schwendener N (2013) Experimental characterization of cement-bentonite interaction using core infiltration techniques and $4 \mathrm{D}$ computed tomography. Physics and Chemistry of the Earth, Parts A/B/C DOI http://dx.doi.org/10.1016/j.pce.2013.11.002

Dridi W (2013) Analysis of effective diffusivity of cement based materials by multi-scale modelling. Materials and Structures 46(1-2):313-326, DOI 10.1617/s11527-012-9903-5

Du X, Jin L, Ma G (2014) A meso-scale numerical method for the simulation of chloride diffusivity in concrete. Finite Elements in Analysis and Design 85:87 - 100, DOI http://dx.doi.org/10.1016/j.finel.2014.03.002

Goto S, Roy D (1981) Diffusion of ions through hardened cement pastes. Cement and Concrete Research 11(5-6):751-757

Hadermann J, Heer W (1996) The grimsel (switzerland) migration experiment: integrating field experiments, laboratory investigations and modelling. Journal of Contaminant Hydrology 21:87-100, DOI http://dx.doi.org/10.1016/0169-7722(95)00035-6

Haggerty R, McKenna S, Meigs L (2000) On the late-time behavior of tracer test breakthrough curves. Water Resources Research 36(12):3467-3479, DOI 10.1029/2000WR900214

Heer W (2004) Nuclide transport and diffusion in veins and fracture flow. nagra technical report ntb 04-03. Tech. rep., Nagra, Wettingen, Switzerland

Jakob A, Mazurek M, Heer W (2003) Solute transport in crystalline rocks at Äspö- II : Blind predictions, inverse modelling and lessons learnt from test $\{\mathrm{STT} 1\}$. Journal of Contaminant Hydrology 61:175 - 190, DOI http://dx.doi.org/10.1016/S0169-7722(02)00136-5

Jenni A, Mäder U, Lerouge C, Gaboreau S, Schwyn B (2013) In situ interaction between different concretes and opalinus clay. Physics and Chemistry of the Earth, Parts A/B/C DOI http://dx.doi.org/10.1016/j.pce.2013.11.004

Kamali-Bernard S, Bernard F, Prince W (2009) Computer modelling of tritiated water diffusion test for cement based materials. Computational Materials Science 45(2):528-535

Mäder U, Waber H, Gautschi A (2004) New method for porewater extraction from claystone and determination of transport properties with results for Opalinus Clay (Switzerland). In: Wanty, RB, Seal, RR (Eds), Proceedings WRI-10 (11th International Symposium on Water-Rock Interaction) Balkema, Saratoga Springs, New York, USA pp 445-448

Mäder U, Fierz T, Frieg B, Eikenberg J, Rüthi M, Albinsson Y, Möri A, Ekberg S, Stille $\mathrm{P}$ (2006) Interaction of hyperalkaline fluid with fractured rock: Field and laboratory experiments of the HPF project (Grimsel Test Site, Switzerland). Journal of Geochemical 
Exploration 90(1-2):68-94

Marquardt D (1963) An algorithm for least-squares estimation of nonlinear parameters. Journal of the Society for Industrial and Applied Mathematics 11(2):431-441, DOI 10.1137/0111030, http://dx.doi.org/10.1137/0111030

Scrivener K, Crumbie A, Laugesen P (2004) The interfacial transition zone (ITZ) between cement paste and aggregate in concrete. Interface Science 12:411-421, DOI 10.1023/B:INTS.0000042339.92990.4c

Slooten LJ, Batlle F, Carrera J (2010) An XML based problem solving evirontment for hydrological problems. XVIII International Conference on Water Resources (CMWR), Barcelona, Spain pp 1-8

Soler JM, Mäder UK (2007) Mineralogical alteration and associated permeability changes induced by a high-ph plume: Modeling of a granite core infiltration experiment. Applied Geochemistry 22(1):17 - 29, DOI http://dx.doi.org/10.1016/j.apgeochem.2006.07.015

Soler JM, Mäder UK (2010) Cement-rock interaction: Infiltration of a high-ph solution into a fractured granite core. Geologica Acta 8:221-233, DOI DOI: 10.1344/105.000001531

Taylor HFW (1997) Cement Chemistry. Thomas Telford Ltd

Tits J, Jakob A, Wieland E, Spieler P (2003) Diffusion of tritiated water and ${ }^{22} \mathrm{Na}^{+}$through non-degraded hardened cement pastes. Journal of Contaminant Hydrology 61(1-4):45-62

Villar MV, Martín PL, Barcala JM (2009) Caracterización del material de cobertera y el hormigón del C.A. El Cabril. Technical report CIEMAT/DMA/2G205/03/09, CIEMAT, Madrid, $55 \mathrm{pp}$

Zuloaga P, Andrade C, Saaltink MW (2006) Long term water flow scenario in low-level waste disposal vaults, with particular regard to concrete structures en El Cabril, Cordoba, Spain. JPhys IV, France 
a) Deuterium
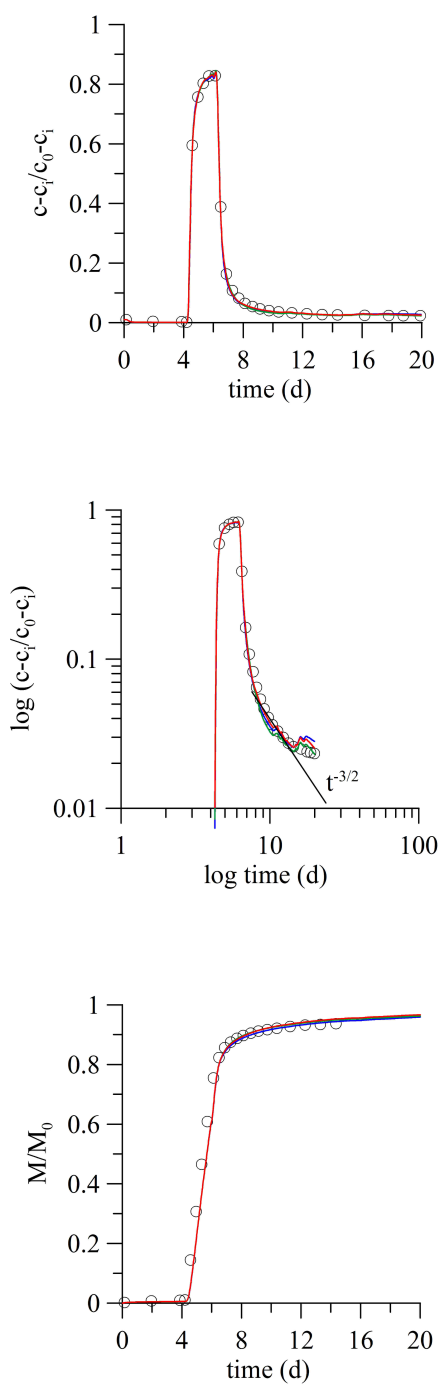

b) Bromide
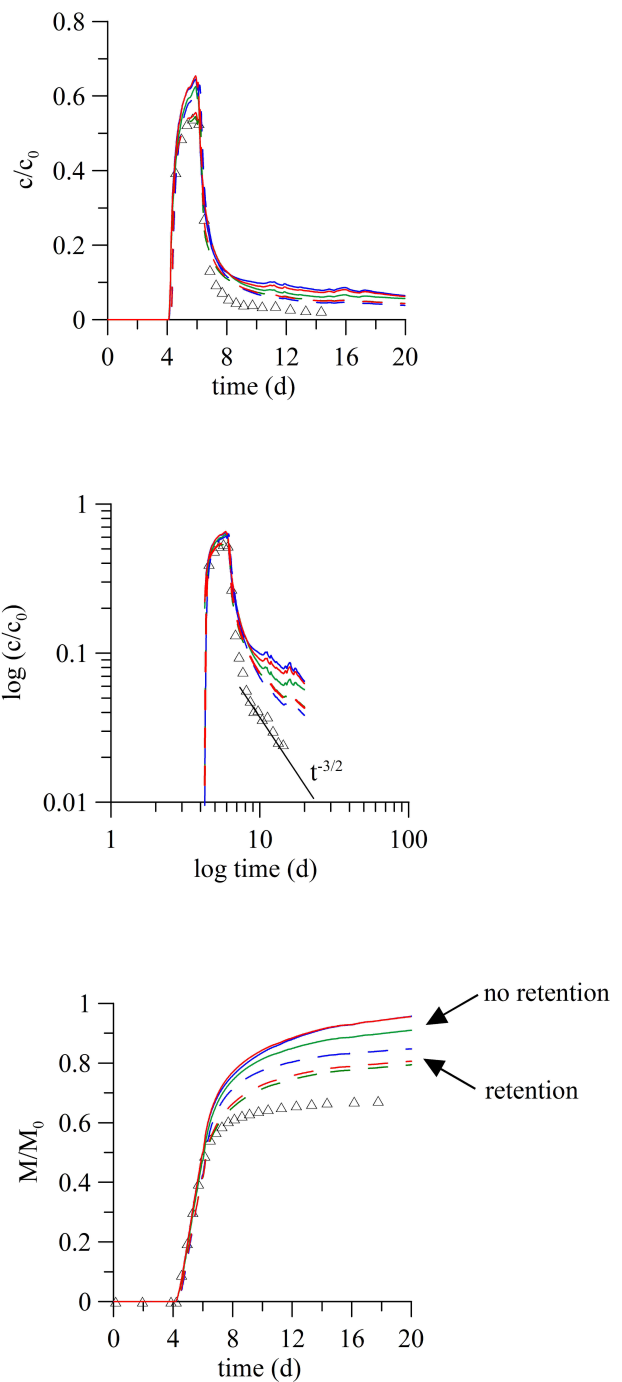

Fig. 5 Evolution of relative concentration, log-log plot of the breakthrough curves and cumulative mass for deuterium and bromide. Double porosity model results (lines) are compared with the experimental data (points). 
a) Slabs

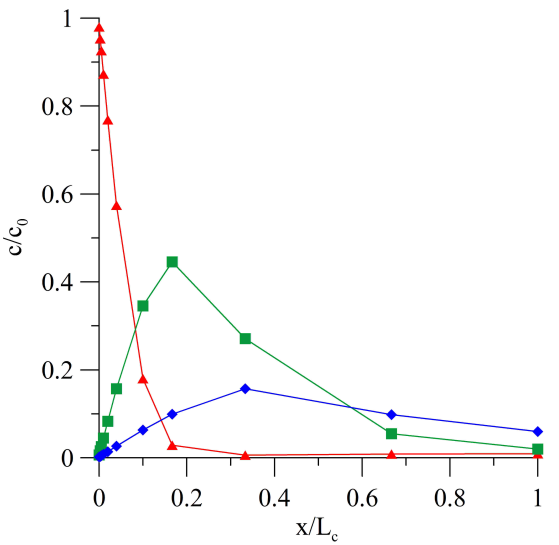

c) Tubes

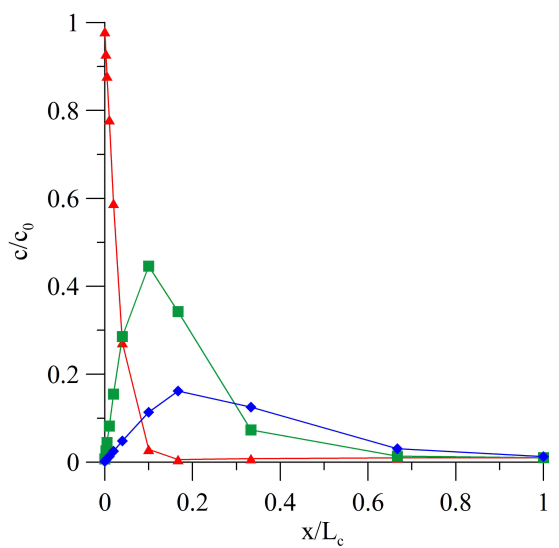

b) Spheres

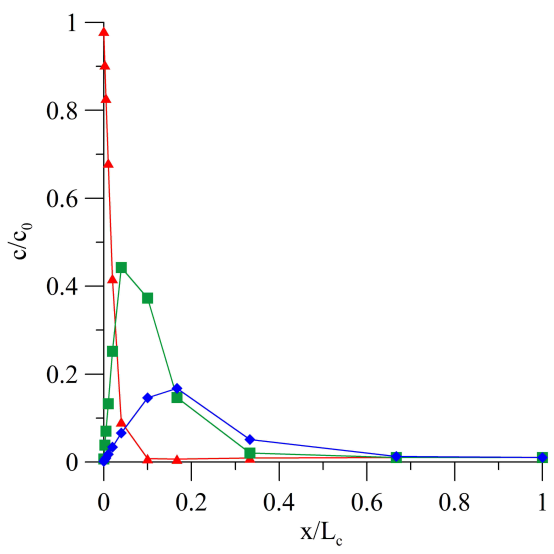

Fig. 6 Relative concentration against dimensionless length (immobile zone) for all geometries in the deuterium model 